\title{
INFLUENCE OF HEAT TREATMENT ON MECHANICAL PROPERTIES OF AL- 2024 REINFORCED WITH TITANIUM DI-OXIDE
}

\section{DR MAHESH T $S^{1} \&$ MANJULA $S^{2}$}

${ }^{1}$ Assistant Professor, Department of Mechanical Engineering, Government Engineering College Hassan, Karnataka, India

${ }^{2}$ Assistant Professor, Department of Mechanical Engineering, Government Engineering College Hassan, Karnataka, India

ABSTRACT
A composite material can be defined as a combination of two or more constituent materials (individual materials) with
different physical or chemical properties, and which remain separate and distinct on a microscopic or macroscopic level
within the finished structure. In other words, the constituents do not dissolve or merge into each other, although they act
together to form a single material. In this project Al-2024 Metal Matrix Composites (MMC) will be produced using stir
casting method by adding Titanium di-oxide (TiO2) reinforcement with varying weight percentages of $1.5,3$ and 4.5.
Liquid state fabrication of metal matrix composites involves incorporation of dispersed phase into a molten matrix metal,
followed by its solidification. In order to provide high level of mechanical properties of the composite, good interfacial
bonding between the dispersed phase and the liquid matrix should be obtained. The casted composite will be subjected to
heat treatment process and then the mechanical properties such as hardness, compression strength and tensile strength
will be studied.
KEYWORDS: MMC, Stir casting, Heat Treatment, Hardness

Received: Jun 09 2021; Accepted: Jun 29, 2021; Published: Jul 13, 2021; Paper Id.: IJMPERDAUG202121

\section{INTRODUCTION}

A composite material can be defined as a combination of two or more constituent materials (individual materials) with different physical or chemical properties, and which remain separate and distinct on a microscopic or macroscopic level within the finished structure. In other words, the constituents do not dissolve or merge into each other, although they act together to form a single material. Most composites are made up of just two materials, representing as matrix and reinforcement. It has been already stated that a composite is a mixture of two or more distinct have to be satisfied before a material is said to be composite.

\section{OBJECTIVES AND METHODOLOGY}

\subsection{Objectives}

- To fabricate the Aluminium 2024 metal matrix reinforced using titanium di-oxide as reinforcement with varying percentage.

- To study the mechanical properties of the produced composite materials.

- Secondary processing of produced metal matrix composites.

- Comparing result with previous results.

\subsection{Methodology}

The methodology is explained in the flow chart as shown below: 


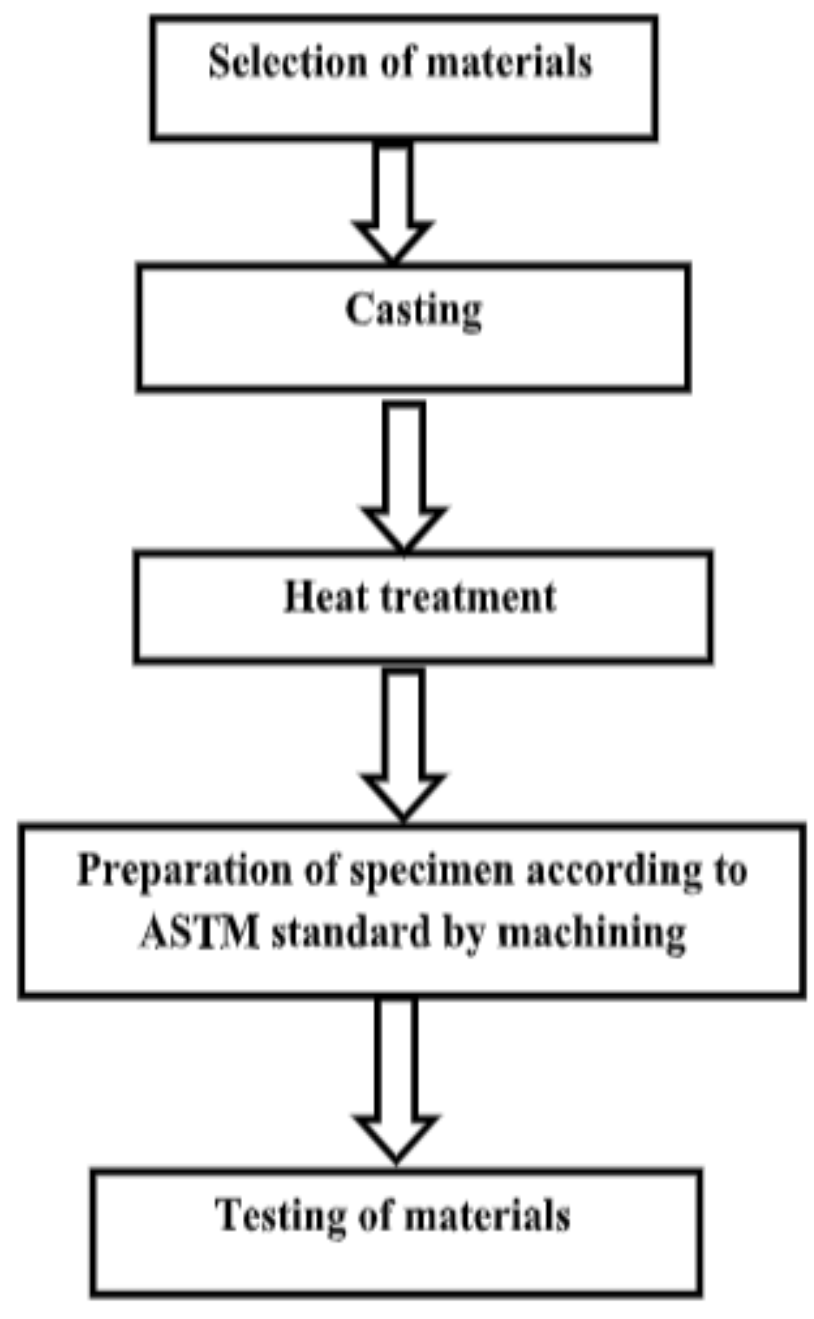

Figure 2.2: Flow diagram of Methodology

1.3 Selection of Materials:

2.3.1 Aluminium Alloy 2024

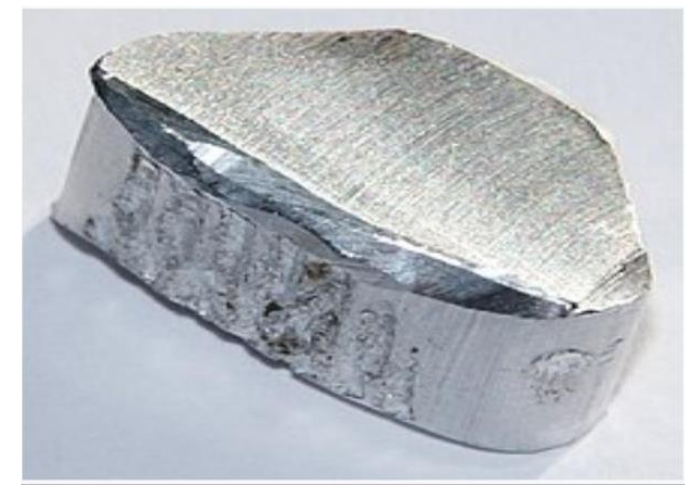

Figure 2.3.1: Aluminium 2024

2024 Aluminium alloy is an Aluminium alloy with copper as the primary alloy element. It is used in applications requiring high strength to weight ratio as well as good fatigue resistance and has average mach inability. 


\subsubsection{Titanium Di-oxide $\left(\mathrm{TiO}_{2}\right)$}

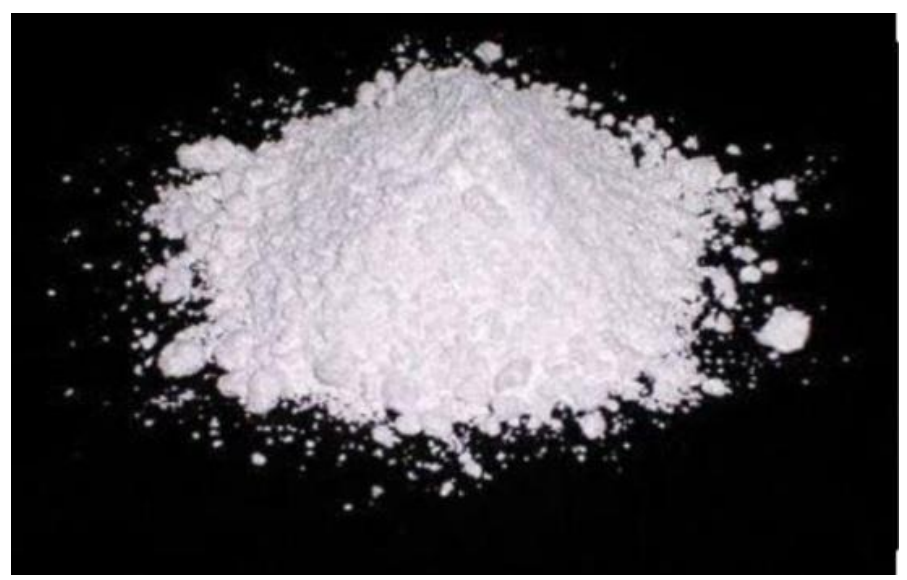

Figure 2.3.2: Titanium Di-Oxide

Titanium Di-oxide also known as titanium (1V) oxide or Titania, is the naturally occurring oxide of titanium and its chemical formula is $\mathrm{TiO}_{2}$

\section{FABRICATION OF COMPOSITES}

\section{Preparation of Composites Via Stir Casting}

First of all required amount of Aluminium 2024 is added to the furnace, the temperature of the furnace is raised above the melting point of the Aluminium 2024 and maintained at that temperature till the molten state is obtained.
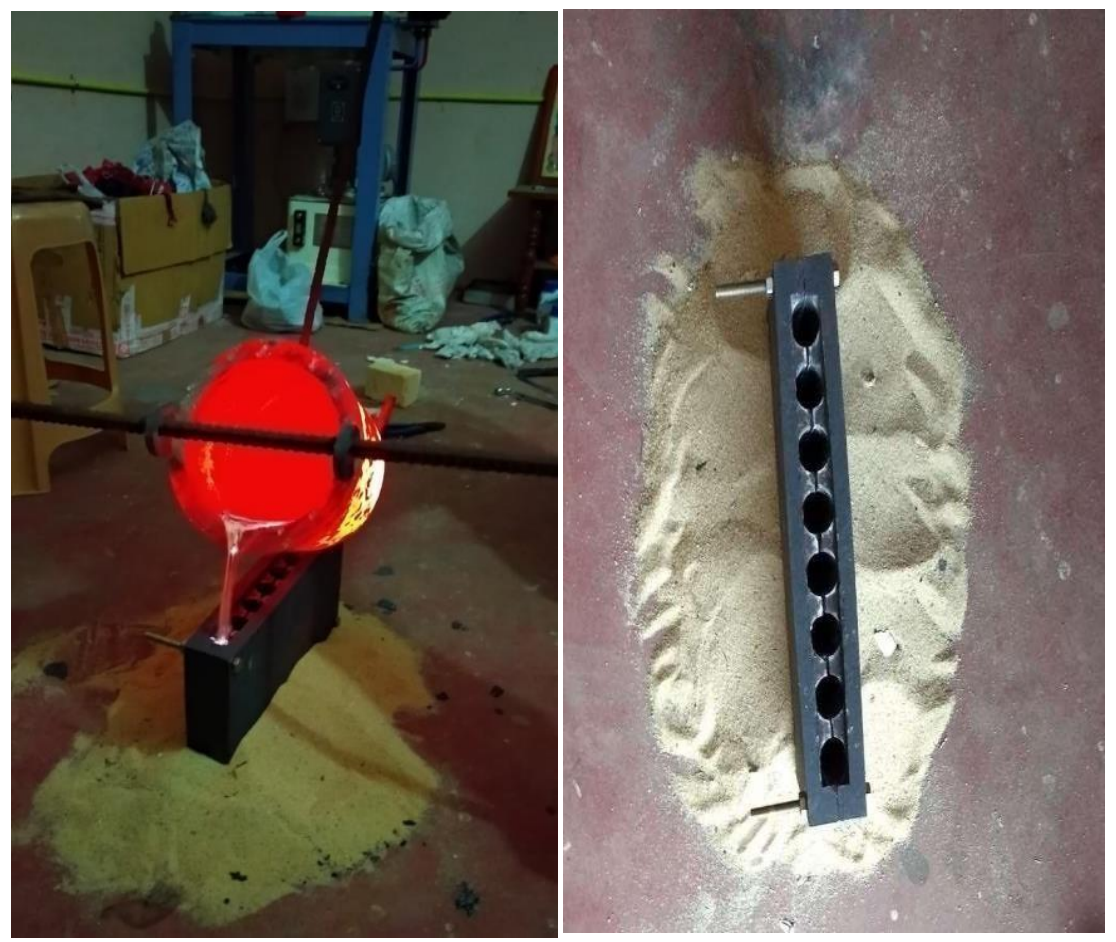

Figure 3.1.1: Pouring Molten Composites 

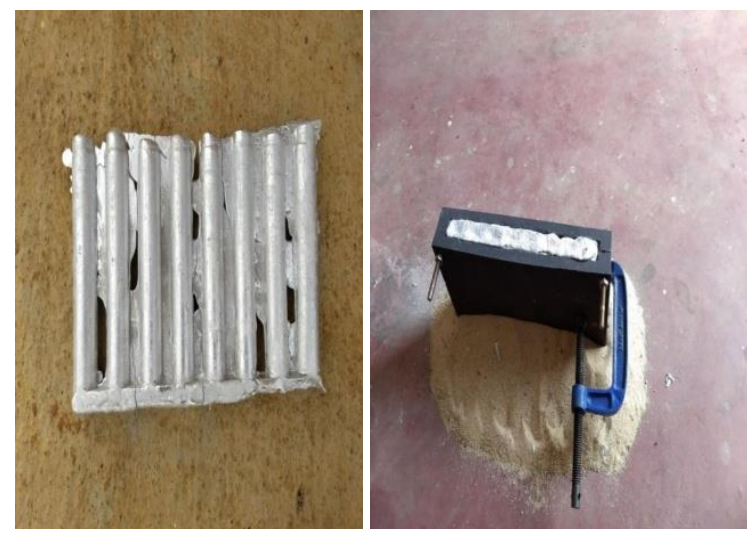

Figure 3.1.2: Casted Cylindrical Rods of $\mathrm{ALTiO}_{2}$

\section{HEAT TREATMENT PROCESS}

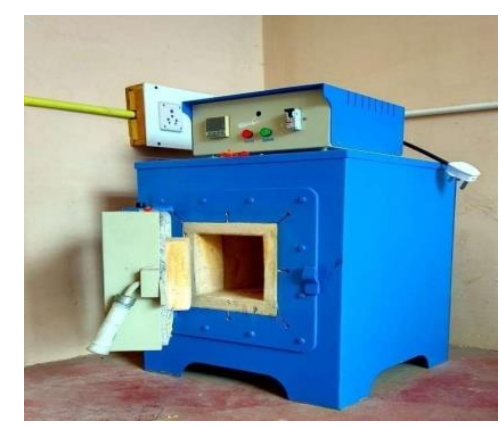

Figure 4.1.1: Muffle Furnace

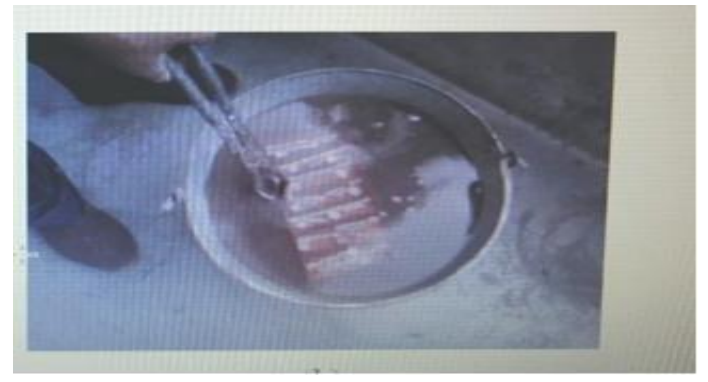

Figure 4.1.2: Heat Treatment Process

\section{Age Hardening}

The Aluminium composites were heat treated and tempered to $\mathrm{T} 6$ condition. That is the samples were heated at $530^{\circ} \mathrm{C}$ for 3 hours and then immediately quenched in water at room temperature and finally were artificially aged in the furnace at $180^{\circ} \mathrm{C}$ for 5 hours and then air cooled to room temperature.

\section{SPECIMEN PREPARATION AND TESTING}

\subsection{Tensile Test}

Specimen Preparation - The tensile specimens were machined according to ASTM E8/8M standards with the aid of especially sharp cutting tools, to avoid any other additional deformation or overheating during machining. The cast material of different composition was turned using $\mathrm{CNC}$ lathe for required dimensions using high speed steel tool. The initial diameter and gauge length was measured using measuring equipment and was recorded for further calculations. 


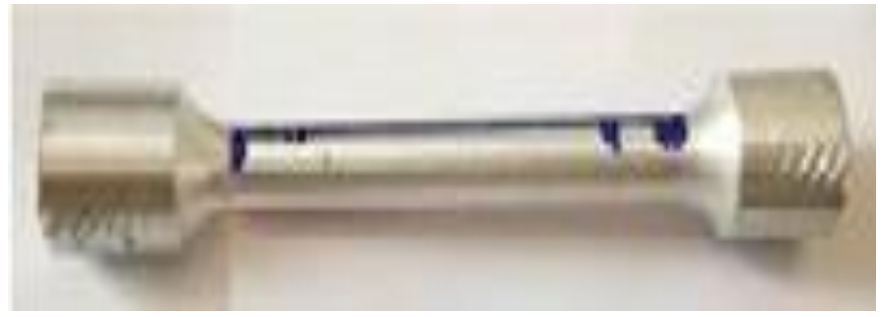

Tensile Test Specimen Before Testing
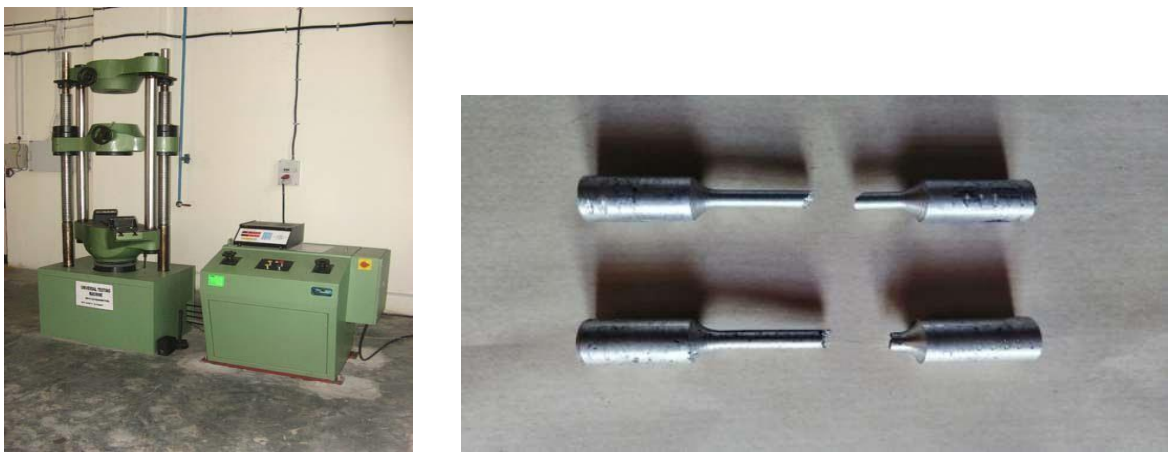

Figure 5.1: Universal Testing Machine Specimen after Testing
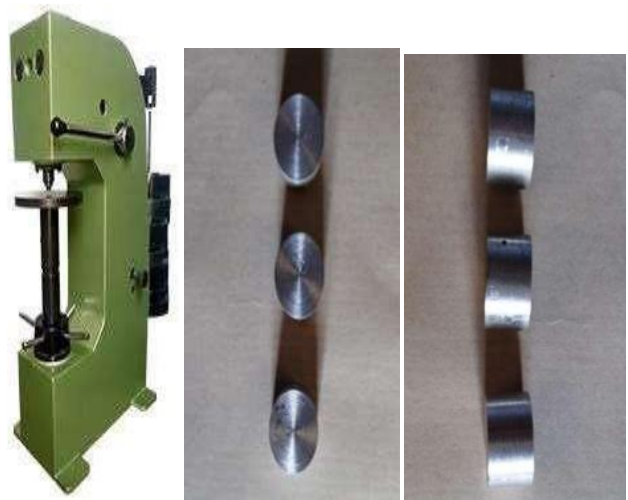

Figure 5.2: Brinell Hardness Testing Device Testing Specimen

\section{After Testing Specimen}

\subsection{Hardness Test: Specimen Preparation}

The Hardness specimens were machined according to the ASTME10 standards using CNC lathe for required dimensions using high speed steel tool. Brinell hardness test was performed on this sample. The test was carried out at different locations in order to contradict the possible effect of indenter resting on the harder particles.

\section{Compression Test}

Specimen Preparation - The Compression specimens were machined according to ASTM E9-09 standards with the aid of especially sharp cutting tools, to avoid any other additional deformation or overheating during machining. The cast material of different composition was turned using CNC lathe for required dimensions using high speed steel tool. The initial diameter and gauge length were measured using measuring equipment and was recorded for further calculations. 


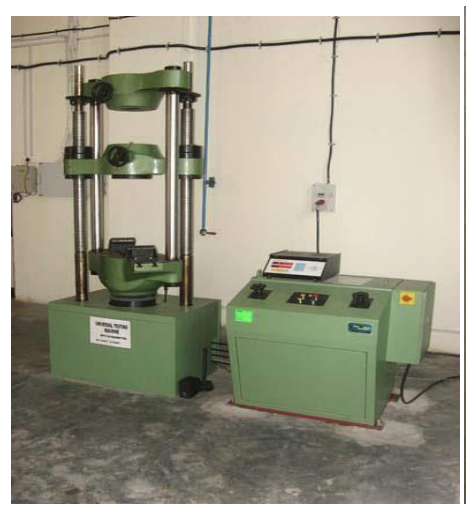

Figure 5.3: Compression Testing Equipment

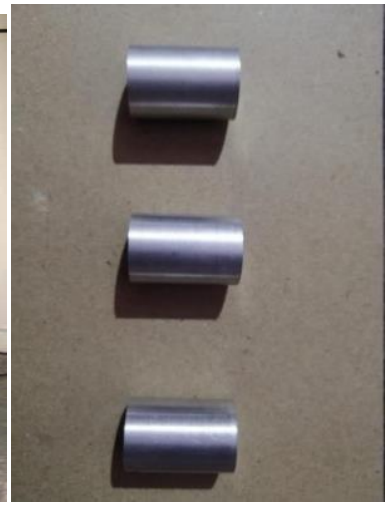

Testing Specimen

\section{RESULTS AND DISCUSSION}

\subsection{Tensile Test}

Following Table 6.1(a) and 6.1(b) shows the different values of tensile strength with varying \% of reinforcements without and with heat treatment respectively.

Table 6.1(a): Values of Tensile Strength for Varying Percentage of $\mathrm{TiO}_{2}$ without Heat Treatment

\begin{tabular}{|c|c|c|}
\hline SL.NO & $\begin{array}{c}\text { Samples with Varying Composition } \\
\text { (Without Heat Treatment) }\end{array}$ & UTS(Mpa) \\
\hline 1 & AL-2024 & 126.13 \\
\hline 2 & AL-2024+1.5\%TiO2 & 149.75 \\
\hline 3 & AL-2024+3\%TiO2 & 166.93 \\
\hline 4 & AL-2024+4.5\%TiO2 & 193.56 \\
\hline
\end{tabular}

From the Table 6.1(a). it is evident that the tensile strength of the sample i.e. Al-2024 is found to be 126.13 MPa, when the sample was added with the $\mathrm{TiO}_{2}$ reinforcements in varying proportions i.e $1.5 \%, 3 \%$ and $4.5 \%$ the tensile properties also increased accordingly i.e. 149.75 Mpa, 166.93 MPa and 193.56 MPa.

Table 6.1(b): Values of Tensile Strength for Varying Percentage of $\mathrm{TiO}_{2}$ with Heat Treatment

\begin{tabular}{|c|c|c|}
\hline SL.NO & $\begin{array}{c}\text { Samples with Varying Composition (With } \\
\text { Heat Treatment) }\end{array}$ & UTS(Mpa) \\
\hline 1 & AL-2024 & 151.10 \\
\hline 2 & AL-2024+1.5\%TiO2 & 174.56 \\
\hline 3 & AL-2024+3\%TiO2 & 202.96 \\
\hline 4 & AL-2024+4.5\%TiO2 & 220.15 \\
\hline
\end{tabular}

Table 6.1(b). represents the tensile strength of the samples which are subjected to the Secondary Heat Treatment process. Here an increase can be seen in the tensile strength, as Al-2024 measured 151.10 Mpa for its tensile strength and the tensile strength of $\mathrm{Al} 2024$ with $1.5 \%, 3 \%$ and $4.5 \%$ of TiO2 reinforcement was found to be 174.56 Mpa, 202.96 Mpa and 220.15 MPa respectively. 


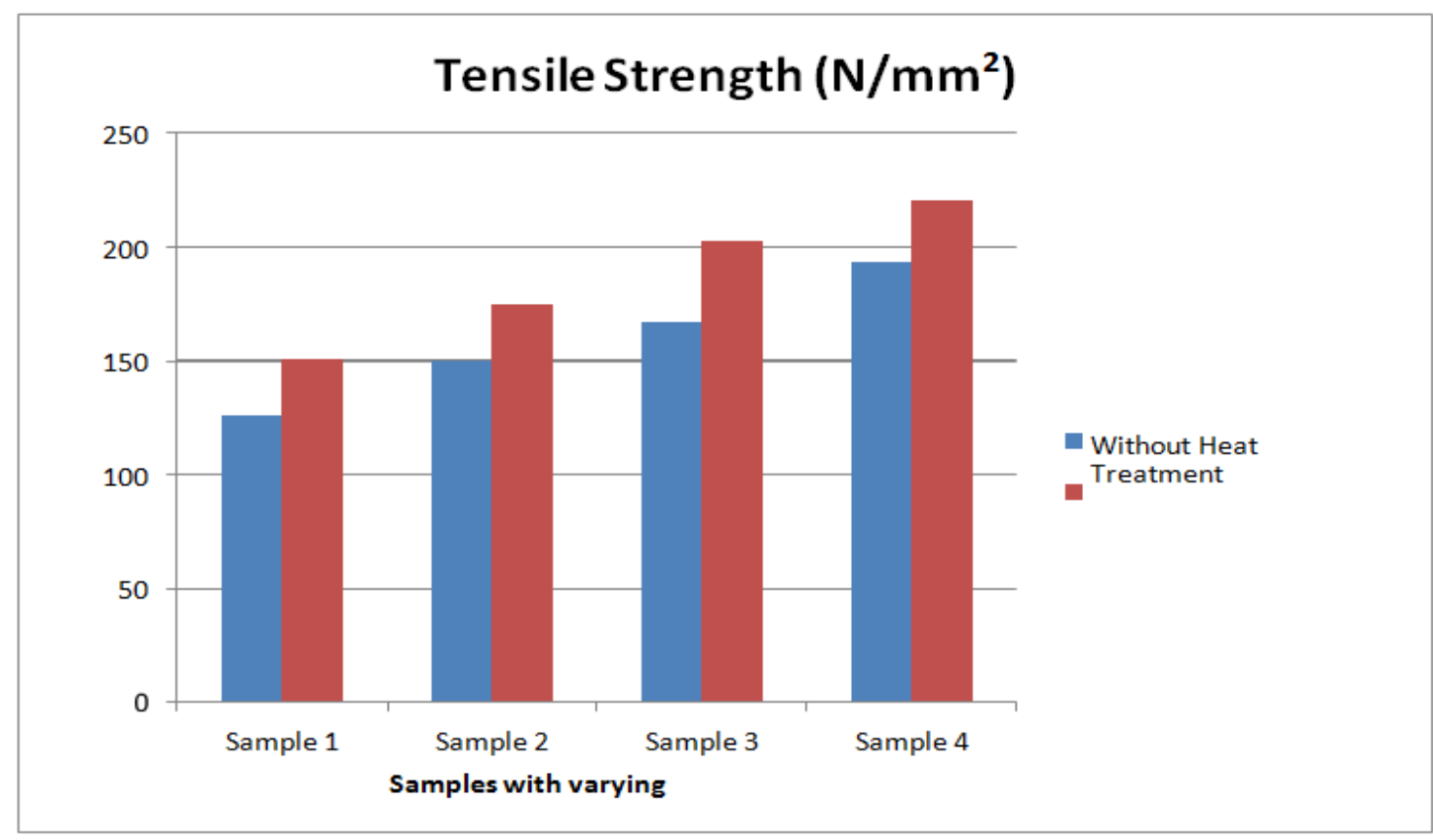

Figure 6.1: Comparison of Tensile Strength Values for without and with Heat Treatment Process

From the above figure 6.1, we can say that or conclude that tensile strength values of Aluminium 2024 increases with increasing percentage of added reinforcement that is $\mathrm{TiO}$. The figure also shows that the Reinforced $\mathrm{Al}-2024$ with $\mathrm{TiO}_{2}$ 's tensile strength will be increased after the heat treatment process.

\subsection{Hardness Test}

The following Table 6.2(a) and 6.2(b) show the different hardness values for varying $\%$ of reinforcements without and with heat treatment respectively.

Table 6.2(a) Hardness Values for Varying Percentage of TiO2 without Heat Treatment

\begin{tabular}{|c|c|c|}
\hline SL.NO & $\begin{array}{c}\text { Samples with Varying Composition } \\
\text { (Without Heat Treatment) }\end{array}$ & BHN \\
\hline 1 & AL-2024 & 68 \\
\hline 2 & AL-2024+1.5\%TiO2 & 76 \\
\hline 3 & AL-2024+3\%TiO2 & 91 \\
\hline 4 & AL-2024+4.5\%TiO2 & 98 \\
\hline
\end{tabular}

From the Table 6.2(a). it is evident that the Hardness of the sample i.e. Al-2024 is found to be 68 BHN, when the sample was added with the $\mathrm{TiO}_{2}$ reinforcements in varying proportions i.e 1.5\%, 3\% and $4.5 \%$ the Hardness also increased accordingly i.e. $76 \mathrm{BHN}, 91 \mathrm{BHN}$ and $98 \mathrm{BHN}$ 


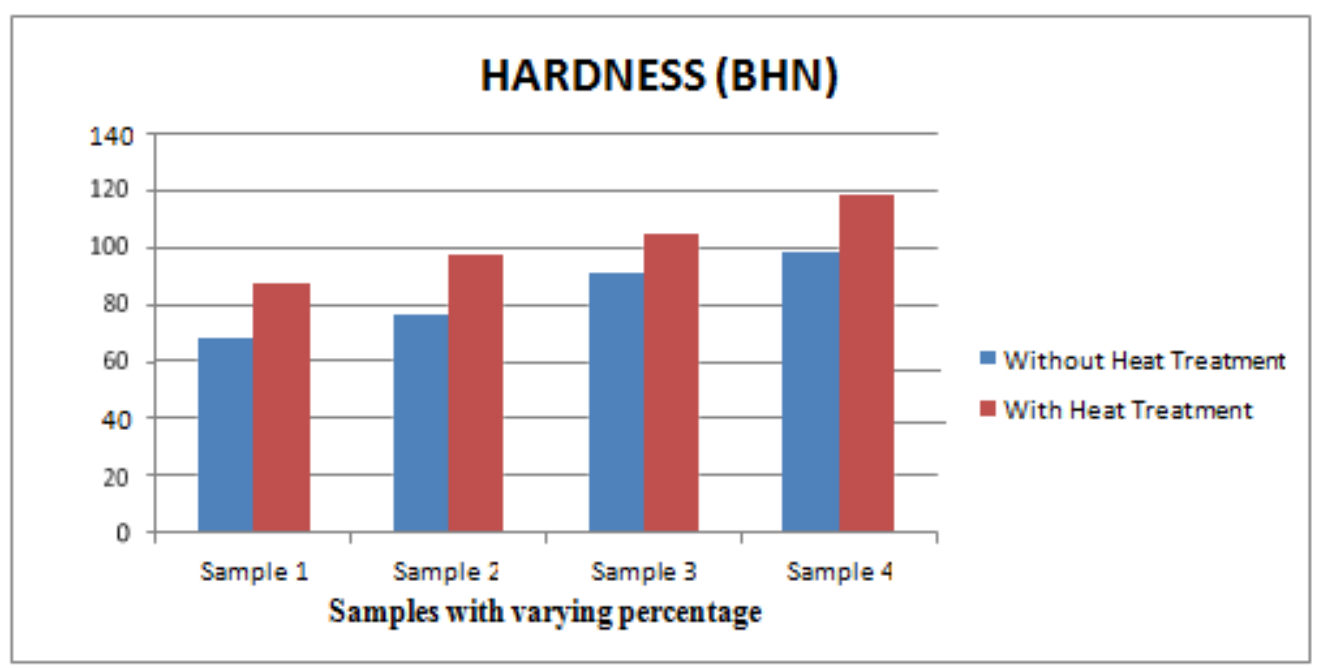

Figure 6.2: Comparison of Hardness Values for without and with Heat Treatment Process

Table 6.2(b): Hardness Values for Varying Percentage of TiO2 with Heat Treatment

\begin{tabular}{|c|c|c|}
\hline SL.NO & $\begin{array}{c}\text { Samples with Varying Composition (With } \\
\text { Heat Treatment) }\end{array}$ & BHN \\
\hline 1 & $\mathrm{AL}-2024$ & 87 \\
\hline 2 & $\mathrm{AL}-2024+1.5 \% \mathrm{TiO}_{2}$ & 97 \\
\hline 3 & $\mathrm{AL}-2024+3 \% \mathrm{TiO}_{2}$ & 105 \\
\hline 4 & $\mathrm{AL}-2024+4.5 \% \mathrm{TiO}_{2}$ & 118 \\
\hline
\end{tabular}

Table 6.2(b). represents the Hardness of the samples which are subjected to the Secondary Heat Treatment process. Here an increase can be seen in the tensile strength, as Al2024 measured 87 BHN for its Hardness and the hardness of Al2024 with $1.5 \%, 3 \%$ and $4.5 \%$ of $\mathrm{TiO} 2$ reinforcement was found to be $97 \mathrm{BHN}, 105 \mathrm{BHN}$ and $118 \mathrm{BHN}$ respectively.

From the above fig.6.2, we can say that or conclude that hardness values of Aluminium 2024 increases with increasing percentage of added reinforcement that is $\mathrm{TiO}_{2}$. The figure also shows that the Reinforced $\mathrm{Al}-2024$ with $\mathrm{TiO}_{2}$ 's hardness value will be increased after the heat treatment process.

\subsection{Compression Test}

The following Table 6.3(a) and 6.3(b) shows the different compression strength values for varying \% of reinforcements without and with heat treatment respectively.

Table 6.3(a): Values of Compression Strength for Varying Percentage of TiO2 without Heat Treatment

\begin{tabular}{|c|c|c|}
\hline SL.NO & $\begin{array}{c}\text { Samples with Varying Composition } \\
\text { (Without Heat Treatment) }\end{array}$ & CS(Mpa) \\
\hline 1 & AL-2024 & 298.81 \\
\hline 2 & AL-2024+1.5\%TiO2 & 345.42 \\
\hline 3 & AL-2024+3\% TiO2 & 387.67 \\
\hline 4 & AL-2024+4.5\%TiO2 & 430.63 \\
\hline
\end{tabular}

From the Table 6.3(a). it is evident that the compression strength of the sample i.e. Al-2024 is found to be 298.81 $\mathrm{MPa}$, when the sample was added with the $\mathrm{TiO}_{2}$ reinforcements in varying proportions i.e $1.5 \%, 3 \%$ and $4.5 \%$ the compression properties also increased accordingly i.e. 345.42 Mpa, 387.67 MPa and 430.63 MPa. 
Table 6.3(b): Values of Compression Strength for Varying Percentage of TiO2 with Heat Treatment

\begin{tabular}{|c|c|c|}
\hline SL.NO & $\begin{array}{c}\text { Samples with Varying Composition } \\
\text { (Without Heat Treatment) }\end{array}$ & CS(Mpa) \\
\hline 1 & AL-2024 & 321.62 \\
\hline 2 & AL-2024+1.5\%TiO2 & 365.15 \\
\hline 3 & AL-2024+3\%TiO2 & 398.56 \\
\hline 4 & AL-2024+4.5\%TiO2 & 463.21 \\
\hline
\end{tabular}

Table 6.3(b). represents the compression strength of the samples which are subjected to the Secondary Heat Treatment process. Here an increase can be seen in the compression strength, as Al-2024 measured 321.62 Mpa for its compression strength and the compression strength of $\mathrm{Al} 2024$ with $1.5 \%, 3 \%$ and $4.5 \%$ of $\mathrm{TiO}_{2}$ reinforcement was found to be 365.15 Mpa, 398.56 Mpa and 463.21 MPa respectively.

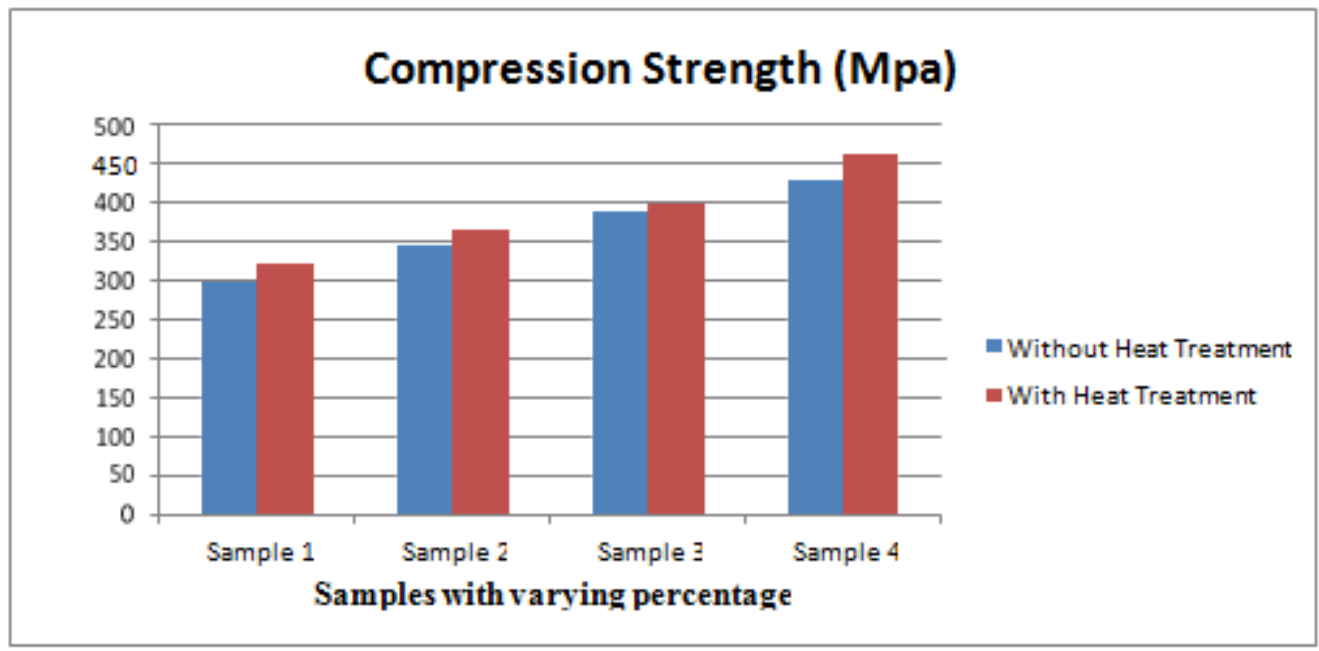

Figure 6.3: Comparison of Compressive Strength Values for without and with Heat Treatment Process

From the above fig.6.3, we can say that or conclude that compression strength values of Aluminium 2024 increases with increasing percentage of added reinforcement that is $\mathrm{TiO}_{2}$. The figure also shows that the Reinforced $\mathrm{Al}-2024$ with $\mathrm{TiO}_{2}$ 's compression strength will be increased after the heat treatment process.

\section{CONCLUSIONS}

- The composite product of aluminium-2024 reinforced with titanium dioxide was successfully produced by stir casting process.

- The obtained composite exhibited higher value of tensile strength, hardness and compression strength.

- High tensile strength was obtained when the secondary heat treatment process was carried out for Al-2024 with $\mathrm{TiO}_{2}$

- High hardness value was obtained when secondary heat treatment process was carried out for $\mathrm{Al}-2024$ with $\mathrm{TiO}_{2}$

- High compression strength was obtained when the secondary heat treatment process was carried out for Al-2024 with $\mathrm{TiO}_{2}$ 
- Secondary heat treatment process improved the mechanical behavior of the samples due to the improved microstructure which is clearly shown in the results obtained

\section{REFERENCES}

1. Diptikanta Das, Purna Changra Mishra, Sarajit Sing and Swati Pattanail, fabrication and heat treatment of ceramic reinforcement aluminium matrix composites a review international of mechanical and material engineering

2. Pradyumna Viswakarma, Sanjay Soni \& P. M. Mishra, “An Effect of Reinforcement and Heat Treatment on AA7075 Metal Matrix Composite - A Review”, International Journal of Mechanical and Production Engineering Research and Development (IJMPERD) , Vol. 8, Issue 6, pp, 275-288

3. Preetam Kulkarni, Evaluation of mechanical properties of AL2024 based hybrid metal, IOSR journal of mechanical and civil engineering (ISOR JMCE)

4. Anantha Krishna Somayaji \& Narasimha Marakala, "Effect of T6 Heat Treatment on Hardness Wear and Fatigue Behaviour of Nickel Coated Carbon Fiber Reinforced Al-7079 MMC”, International Journal of Mechanical and Production Engineering Research and Development (IJMPERD), Vol. 9, Issue 2, pp, 253-264

5. B Zabmatkesh, MH Enayati, F Karimzadeh tribological and microstructural evaluation of friction stir processed Al2024 alloy material and design 31(10),4891-4896,2010

6. O. A. Elhabib, M. Ayad, A. A. Elmasry \& Adel A. Omar, "Heat Treatment of Wear Particles of Automotive Engines to Determine their Materials from Temper Colours", International Journal of Mechanical Engineering (IJME) ISSN 2319-2240 Vol. 2, Issue 2, pp, 31-42

7. T P Bharathesh, C S Ramesh, S M Varma,R Keshavamurthy, influence of heat treatment on tribological properties of hot forged Al6061-TiO2 composites international journal of emerging technology and advanced engineering volume issue 6, june 2013

8. M. Abdelhameed, Ramadan N. Elshaer, Khaled M. Ibrahim, A. Sobh \& M. El-Shennawy, "Microstructure and Mechanical Characteristics of Titanium Alloy TC21 After Heat Treatment”, International Journal of Mechanical Engineering (IJME) , Vol. 10, Issue 1, pp; 49-56

9. Surabhi lata, Ankur Pandey, Ladhansh, Ankit Sharma, Kuldeep Meena, an experimental study and analysis of the mechanical properties of TiO2 reinforced Aluminium (Al5051) composite, ICMPC 2017 